\title{
PERANCANGAN APLIKASI E-COMMERCE BERBASIS ANDROID PADA KELOMPOK SWADAYA MASYARAKAT DESA MARGAKAYA PRINGSEWU
}

\author{
Rita Irviani $^{1}$, Kasmi $^{2}$, Evi Setyorini ${ }^{3}$, Muhamad Muslihudin ${ }^{4}$ \\ ${ }^{1,2}$ Prodi Manajeman Informatika, STMIK Pringsewu \\ ${ }^{3,4}$ Prodi Sistem Informasi, STMIK Pringsewu \\ Jl. Wisma Rini No.09 Pringsewu, Lampung \\ kasmistmikpsw@gmail.com, evisetyorini971@gmail.com, muslihudinstmikpsw@gmail.com
}

\begin{abstract}
Abstrak
E-commerce adalah kegiatan jual beli barang dan jasa melalui penggunaan smartphone dan internet yang biasanya sering di sebut Business to Consumer. Perancangan Aplikasi Berbasis Android untuk Kelompok Swadaya Masyarakat di Desa Margakaya nantinya akan digunakan dalam pemesanan produk kerajinan masyarkat Margakaya Pringsewu. Pengembangan sistem informasi yang di gunakan menggunakan siklus Systems Development Life Cycle dengan tahapan-tahapan yang telah di tentukan. Dari hasil uji sistem didaptakan hasil bahwa sistem ini sangat memantu pemasaran produk uasaha kecil menengah.
\end{abstract}

Kata Kunci : E-Commerce; Website;KSM;Android; Pringsewu;

\begin{abstract}
E-commerce is the activity of buying and selling goods and services through the use of smart phones and the internet is usually often called Business to Consumer. Designing Android-Based Applications for Self-Help Groups in Margakaya Village will be used in ordering handicraft products Margakaya Pringsewu community. Development of information systems that are used using the cycle Systems Development Life Cycle with stages that have been specified. From the results of system test results obtained that this system is very helpful marketing of small and medium-sized products.
\end{abstract}

Keywords : E-Commerce; Website; KSM; Android; Pringsewu; 


\section{Pendahuluan}

Berkembangnya dunia teknologi dan informasi mempengaruai seluruh kehidupan manusia dalam memenuhi kebutuhan hidupnya. Pasar online atau sering disebut juga Elektronik Commerce menjadi peluang baru dan menambah daya saing sistem transaksi pembelian, oleh karena itu sangat di butuhkan dalam menghadapai persaingan pasar untuk mendapatkan hasil yang signifikan dalam menjalankan E-Commerce[1]. Menurut data yang dirilis IDC, hingga september 2013, Android sudah menjadi sistem oprasi paling favorit di indonesia dengan market share sebesar $60 \%$ Jauh meninggalkan BlackBerry yang hanya $30 \%$ Windows phone $(9 \%)$, serta iOS (3\%).

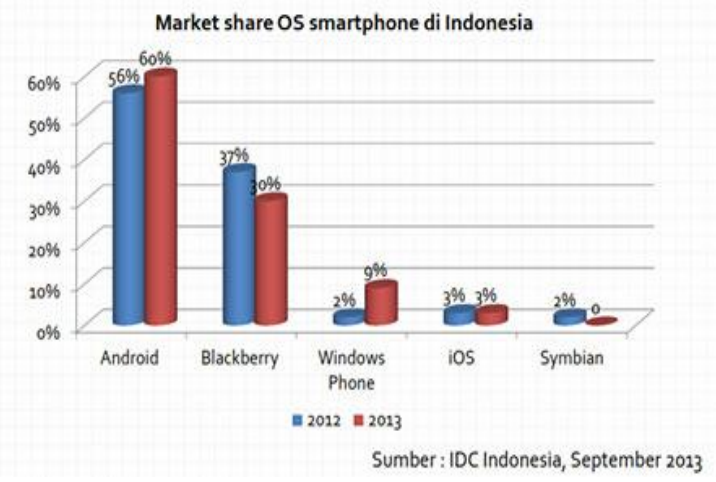

Gambar 1. Market Share OS Smartphone indonesi[2]

Steven Yurie Frediyatama (2014) penelitian ini menggunakan sistem berbasis Could dan ditambahkan fitur lain, untuk menunjang proses lain yang membantu efesiensi kerja lestoran [3]. Muhammad Rifa'i, Tri Listyorini, Anastasya Latubessy (2014) penelitian ini menjelaskan bahwa aplikasi ini memudahkan pada pembeli untuk melihat rumah secara virtual pada katalog yang disediakan sebelum membeli rumah [4]. Febri Nova Lenti (2017) penelitian ini menghasilkan suatu sistem E-commerce B2B-B2C berbasis online untuk antar muka konsumen akhir bertransaksi dan berbasis mobile untuk antar muka antara affiliator dan supplier/pemilik [5].

Dari beberapa penelitian Aplikasi Mobile Commerce dapat langsung melakukan trasaksi pemesanan produk dan beberapa ada yang menggunakan open source yang menggunakan java sebagai bahasa pemrograman sehingga memudahkan pengembangan untuk membuat aplikasi di Android. Berdasarkan penjelasan diatas, karna kelemahan yang sedang berjalan pada sistem informasi pemasaran produk KSM maka akan dibuat sebuah sistem berbasis aplikasi android sebgai media pemasaran dan penjulan produk hasil kerajinan masyarakat.

\section{Tinjauahn Pustaka}

\section{A. Sistem Informasi}

Menurut Ida Nuraida (2008), sistem informasi merupakan perangkat prosedur yang terorganisasi dengan sistematik, bila dilaksanakan akan menyediakan informasi yang dapat dimanfaatkan dalam proses pembuatan keputusan[6][7]. Menurut Al - Bahra Ladjamudin, (2005) Sistem Informasi merupakan satu kesatuan data olahan yang terintegrasi dan saling melengkapi yang menghasilkan output baik dalam bentuk gambar, suara maupun tulisan[8][9][10].

\section{B. Program Aplikasi}

Menurut Dop (2013) Istilah aplikasi berasal dari bahasa inggris application yang berarti penerapan, lamaran ataupun penggunaan sedangkan secara umum, pengertian aplikasi adalah suatu program yang siap untuk digunakan yang dibuat untuk melaksanakan suatu fungsi bagi pengguna jasaaplikasi serta jasa penggunaaplikasi lain yang dapat digunakan oleh pengguna yang akan dituju [11]. Verdy Yasin (2007) menjelaskan Aplikasi adalah suatu subkelas perangkat lunak komputer yang memanfaatkan kemampuan komputer langsung untuk melakukan suatu tugas yang diinginkan pengguna[12].

\section{Android}

Menurut Kasman (2013) Android merupakan sebuah sistem operasi telepon seluler dvn computer tablet layar sentuh (touchscreen) yang berbasis linux. Namun dengan seiring perkembangan android berubah menjadi platform yang begitu cepat dan melakukan inovasi [11].

\section{E-Commerce}

Menurut Loudon (1998) E-Commerce atau Elektronik Commerce ialah suatu proses yang dilakukan konsumen dalam membeli dan menjual berbagai produk secara elekrtonik dari perusahaan ke perusahaan laindengan menggunakan computer sebagai perantara transaksi bisnis yang dilakukan [13][14].

E-Commerce memiliki fungsi untuk mempermudah komunikasi antara produsen, konsumen, pemasaran dan promosi barang atau jasa. Memperluas jangkauan calon konsumen dengan pasar yang luas. Mempermudah proses penjualan dan pembelian. Mempermudah pembayaran karena dapat dilakukan secara online. Mempermudah penyebaran informasi[15][16].

\section{E. KSM ( Kelompok Swadaya Masyarakat)}

Kelompok swadaya masyarakat (KSM) adalah sekelompok orang yang bersepakat untuk saling membantu dan bekerjasama membangun sumber 
keuangan guna mendorong dan mengembangkan usaha produktif dan meningkatkan taraf hidup paraanggota dan keluarga.

KSM atau (Kelompok Swadaya Masyarakat ) adalah sebuah perkumpulan orang yang menyatukan diri secara sukarela dalam kelompok dikarenakan adanya Visi, Kepentingan, dan kebutuhan yang sama sehingga kelompok tersebut memiliki kesamaan tujuan yang ingin dicapai bersama.

\section{Metode Penelitian}

\section{A. Systems Development Life Cycle}

SDLC (Systems Development Life Cycle, Siklus Hidup Pengembangan Sistem) atau Systems Life Cycle (Siklus Hidup Sistem), dalam rekayasa sistem dan rekayasa perangkat lunak, adalah proses pembuatan dan pengubahan sistem serta model dan metodologi yang digunakan untuk mengembangkan sistem-sistem tersebut[17]. Konsep ini umumnya merujuk pada sistem komputer atau informasi. SDLC juga merupakan pola yang diambil untuk mengembangkan sistem perangkat lunak, yang terdiri dari tahap-tahap: rencana(planning), analisis (analysis), desain (design), implementasi (implementation), uji coba (testing) dan pengelolaan (maintenance) [6].

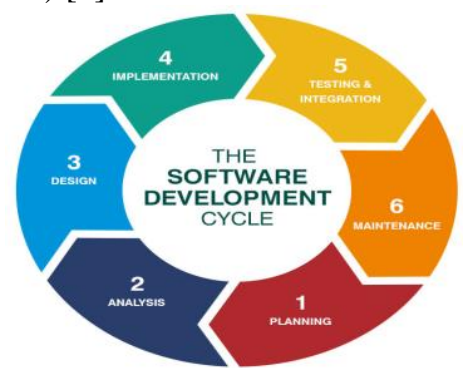

Gambar 2. Systems Development Life Cycle

\section{Pembahasan}

\section{A. Perancangan Sistem}

Flowchart adalah suatu bagan dengan symbolsimbol tertentu dengan symbol-simbol tertentu yang menggambarkan urutan proses secara mendetail dan hubungan antara suatu proses (instruksi) dengan proses lainya dalam suatu program.

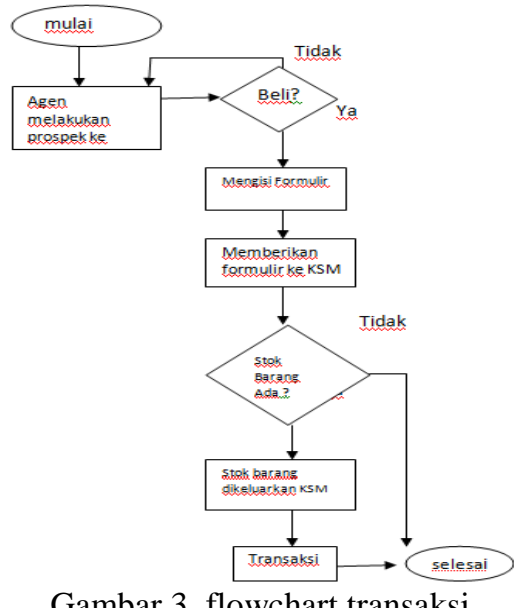

Gambar 3. flowchart transaksi

\section{B. Diagram Kontek}

Diagram konteks pada gambar memperlihatkan interaksi sistem KSM dengan beberapa entitas sebagai pengguna sistem tersebut.

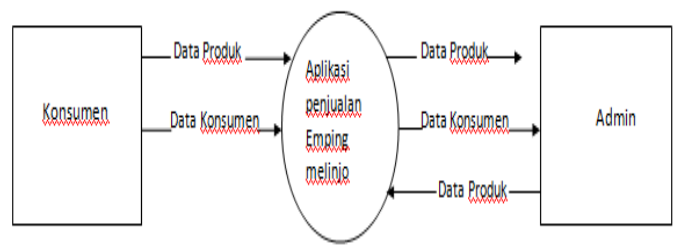

Gambar 4. Diagram Konteks Sistem Aplikasi KSM Gambar diagram konteks aplikasi menunjukan alur data yang mengalir dalam sistem antara pelanggan, pelayan, admin, dan super admin.

\section{Data Flow Diagram}

DFD ini merupakan alat perancangan sistem yang berorientasi pada alur data dengan konsep dekomposisi yang dapat digunakan untuk penggambaran analisa maupun rancangan sistem yang mudah dikomunikasikan oleh profesional sistem kepada pemakai maupun pembuat program.

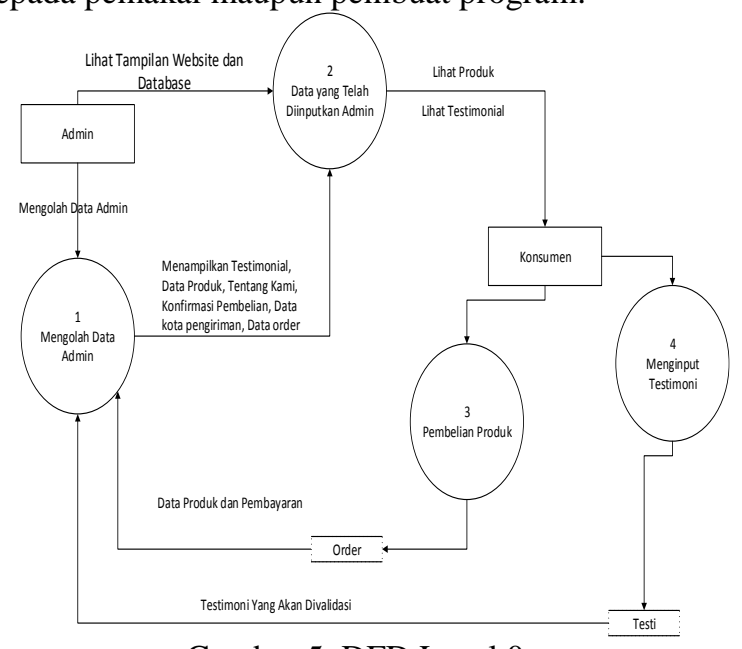

Gambar 5. DFD Level 0 


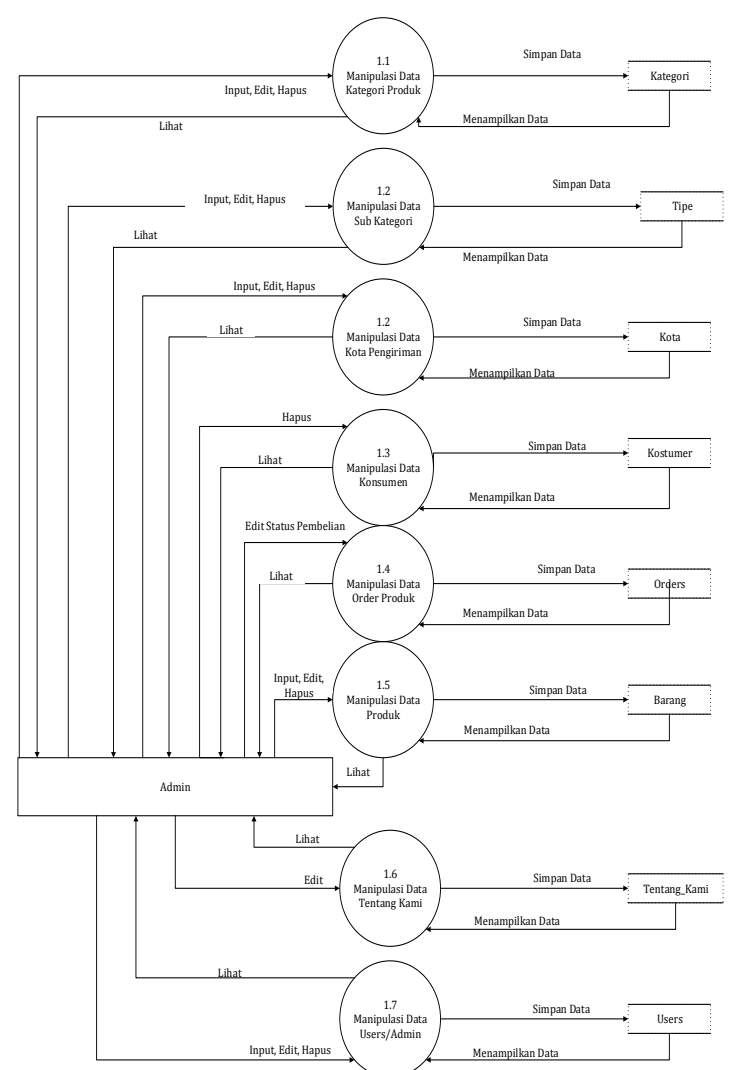

Gambar 6. DFD Level 1

\section{Perancangan Antar muka}

Perancangan Antar Muka merupakan mekanisme komunikasi antara pengguna (User) dengan sistem. Perancangan Antarmuka meliputi perancangan strukturmenu dan perancangan tampilanpada tampilan user.

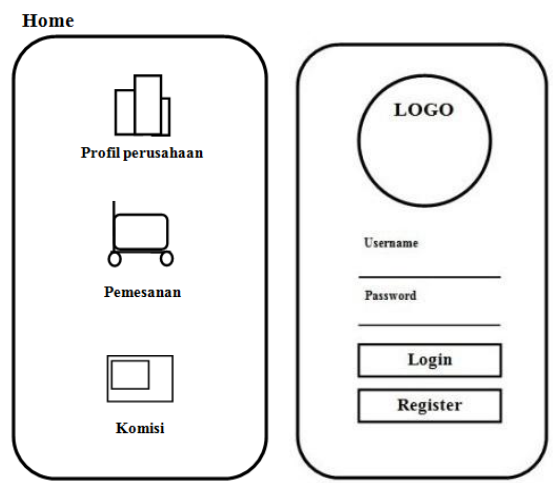

Gambar 7. Desai Antar Muka Aplikasi

\section{E. Implementasi}

Implementasi adalah pelaksanaan atau penerapan, bentuk aksi nyata dalam menjalankan rencana yang telah dirancang dengan matang sebelumnya.

\section{की़े Home}

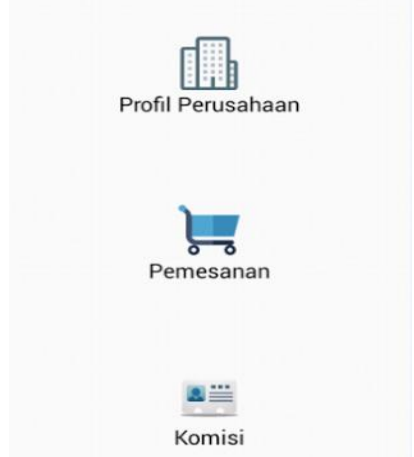

Gambar 8. Implementasi Menu Utama Sistem Android pada KSM

\section{F. Hasil Pembahasan}

Perbandingan dari bulan kebulan yang menggunakan aplikasi dan tidak mengunakan aplikasi (manual), Dari bulan Juni Yang menggunakan sistem manual ada $1 \%$ dan yang menggunakan Sistem Aplikasi terdapat 2\%, Pada bulan Juli yang menggunakan sistem manual terdapat 3\% dan yang menggunakan Sistem Aplikasi terdapat 5\%, Pada bulan Agustus yang menggunakan sistem manual terdapat $2 \%$ dan yang menggunakan sistem Aplikasi terdapat $7 \%$, Dan pada bulan September yang menggunakan sistem Manual terdapat 1\% dan yang menggunakan sistem Aplikasi Terdapat 10\%. Dari semakin meningkatnya perbandingan penjualan terbukti pelanggan lebih tertarik menggunakan sistem aplikasi, karena lemih mudah dan lebih nyaman bagi konsumen dan produsen.

\section{KESIMPULAN}

Dari pengujian dan implemantasi sistem dapat di ambil kesimpulan bawha aplikasi sangat membantu dalam proses transaksi penjualan sehingga pendapatan pelaku usaha di Desa Marga Kaya meningkat.

\section{REFERENSI}

Z. F. Pratama, "Optimasi E-Commerce Berbasis Social Media Martketing Menggunakan Aplikasi Line@ Pada Android Smartphone," SEMNASTEKNOMEDIA, vol. 5, no. 1, pp. 1-6, 2016.

[2] R. F. Isnanto and A. Putra, "Rancang Bangun Aplikasi M-Commerce Berbasis Android Sebagai Media Pemesanan Pada Distro Online," Unsri, pp. 1-12, 2013.

[3] S. Y. Frediyatma, "Aplikasi Pemesanan Makanan Berbasis Cloud dengan Platform Android," Merpati, vol. 2, no. 1, pp. 118-126, 2014.

[4] T. Rifa'i, Muhammad, Listyorini and A. Latubessy, "Penerapan Teknologi Augmented Reality Pada Aplikasi Katalog Rumah Berbasis Android," Pros. SNATIF Ke-1, vol. 1, no. 1, pp. 267-274, 2014.

[5] F. N. Lenti, "Rekayasa proses bisnis pada e-commerce b2b-b2c menggunakan sistem afiliasi," JIKO AKAKOM Yogyakarta, vol. 2, no. 1, pp. 41-49, 2017.

[6] O. Muhammad Muslihudin, Analisi Dan Perancangan Sistem Informasi Menggunakn Model Terstruktur Dan 
UML. Yogyakarta: Andi Offset, 2016

[7] A. Andoyo, "Sistem Informasi Penjualan Makanan Hasil Olahan Kedelai Di Wilayah Gadingrejo Kab Pringsewu Berbasis Web," J. TAM ( Technol. Accept. Model), vol. 1, no. 1, pp. 34-41, 2003

[8] M. Muslihudin and A. Larasati, "Perancangan sistem aplikasi penerimaan mahasiswa baru di stmik pringsewu menggunakan php dan mysql," J. TAM ( Technol. Accept. Model ), vol. 3, no. 1, pp. 12-23, 2014.

[9] M. Muslihudin, "Sistem Informasi Penjualan Batik Basurek Berbasis Web Pada Basurek Collection Bengkulu," J. TAM ( Technol. Accept. Model ), vol. 1, no. 1, p. $59,2013$.

[10] B. B. Nur Aminudin, "Rancang Bangun Model Transaksi On-Line Pada Industri Keripik Pisang Panda Alami Kabupaten Pesawaran Dalam Rangka Meningkatkan Omzet Dan Keuntungan," J. TAM ( Technol. Accept. Model ), vol. 1, no. 1, pp. 27-34, 2013.

[11] M. Inayah, Ayu Rizka, Afriyudi, "Aplikasi Pemesanan Menu Makanan Di Rumah Makan Berbasis Web Service Menggunakan Mobile Android," Univ. Bina Darma, pp. $1-10,2010$.

[12] S. Hartati, N. Ayu Kristiana Dewi, D. Puastuti, M. Muslihudin, and N. Setio Budi, "Sistem Aplikasi Educhat Stmik Pringsewu Berbasis Android Sebagai Media Komunikasi dan Informasi," J. Teknosi UNAND, vol. 3, no. 1, pp. 143-152, 2017.

[13] K. Wiji Susanti and M. M. Noca Yolanda Sari, "Pengembangan Electronic Commerce Dalam Proses Meningkatkan Ukm Pada Dekranasda Kabupaten Pringsewu," Expert, vol. 5, no. 2, pp. 42-47, 2015.

[14] Wulandari, "Analisi Dan Implementasi Sistem ECommerce Furniture Pada Toko Jaya," J. TAM ( Technol. Accept. Model ), vol. 1, no. 1, pp. 15-18, 2013.

[15] M. Muslihudin, W. Wulandari, and Mei Listiarini, "Perancangan Aplikasi Business Berbasis Business to Consumer (B2C) Pada Wisata Kuliner Khas Lampung," J. Keuang. dan Bisnis, vol. 15, no. 1, pp. 54-69, 2017.

[16] D. Irawan, Y. Rahsel, and T. Udin, "Perancangan Electronic Commerce Berbasis B2C Pada Toko Atk Sindoro," J. TAM ( Technol. Accept. Model ), vol. 8, no. 1, pp. 58-62, 2017.

[17] A. Wulandari, Priyono, "E - Commerce Pakaian Pada Distro Bahana Shop," J. TAM ( Technol. Accept. Model ), vol. 3, no. 1, pp. 54-58, 2014.

[18] K. Fergiawan Listianto, Fauzi, Rita Irviani, "Aplikasi ECommerce Berbasis Web Mobile Pada Industri Konveksi Seragam Drumband Di Pekon Klaten Gadingrejo Kabupaten Pringsewu," J. TAM ( Technol. Accept. Model ), vol. 8, no. 2, pp. 146-152, 2017. 